\title{
Educational Technology and Teacher Education: Barriers and Gates in South America
}

\author{
Gustavo Daniel Constantino \\ ICT Department, CIAFIC, CONICET, Buenos Aires, Argentina \\ Email: gustavo.constantino@gmail.com
}

Received 4 April 2014; revised 28 April 2014; accepted 17 May 2014

Copyright (C) 2014 by author and Scientific Research Publishing Inc.

This work is licensed under the Creative Commons Attribution International License (CC BY).

http://creativecommons.org/licenses/by/4.0/

(c) (i) Open Access

\begin{abstract}
Historically, Educational Technology (EdTech) and Teacher Education (TE) have shared a conflicted relationship, particularly where practicing teachers have not been trained in ET in a manner so that they are able to coherently and efficiently incorporate the new educational technology into their classrooms and schools. In Latin America's diverse scenario, our analysis is focused on a scenario consisting of Argentina and Uruguay. In this scenario, we identify the social and cultural context where teacher education and teaching practice take place, the EdTech-related programs with the greatest impact, and the "barriers" hindering access to and the application of EdTech, as well as the "bridges" or "gates" that facilitate their effective incorporation to teaching and learning both at schools and in teacher education. Lastly, we propose some courses of action to reduce these barriers and widen the gates connecting EdTech and school settings.
\end{abstract}

\section{Keywords}

Educational Technology, Teacher Education, Social Inclusion, Digital Literacy, South America, Argentina

\section{Introduction}

Educational Technology (EdTech) is an encompassing term, an "umbrella" concept bringing together countless objects, applications, and knowledge with the use or generation of technology for teaching and learning as their common denominator. The successive definitions of this field of discipline have not escaped criticism and controversy (Lowenthal \& Wilson, 2010).

It should be mentioned that very important theoretical (and practical) differences exist between academic tra- 
ditions in the United States, Europe, and South America. If in the Anglo-Saxon tradition the connection between the reality of "instruction" and the scientific knowledge that comes from its study can be readily apparent, in the Latin American tradition the concept of "teaching" has occupied a prominent position, with "Didáctica" (Didactics, Instructional Science) as its academic knowledge correlation. The distinction here is not just a matter of terminology; rather, it defines an entire epistemological system that delineates what is to be considered and researched. On the other hand, it is important to point out that, in LA, EdTech is viewed as an equivalent to the use of Information and Communication Technologies (ICT) in education. It is for this reason that the use of this label persists, as does the fact of EdTech being reduced to ICTs.

Aside from these issues that concern how this field of discipline is made up, reality reveals the relentless generation of EdTech products and applications that have made their arrival into educational institutions worldwide. This paper will address this phenomenon by showing the contexts and varying impacts of the most ambitious EdTech programs in Latin American's current reality.

\section{A Brief History of Schools and Educational Technology}

The traditional teaching model prevails as the social representation of a teacher's work from elementary school through university, both in society generally, and specifically among teachers in training and practicing teachers. This model has carried on virtually unchanged in the history of Western schools and, even though alternative models do exist, the blooming and evolution of EdTech has not brought about significant changes in this representation. It is not by chance that, for decades now, Distance Education has been viewed as an impoverished mode with limited results that does not compare to face-to-face education (Constantino, 2002, 2010a), even if the use of technology has marked it from the very beginning, allowing it to expand and gain its current strength, in addition to having become an independent field in its own right (Black, 2013).

In the second half of the last century, EdTech at schools developed through the mass media. In successive waves, as a consequence of their impact on and presence in global society, communication technologies were introduced to, and adapted to the needs, ends and constraints of, educational institutions. Radio at first, followed then by television, had their shot in the classrooms, without much in the way of success. The arrival of personal computers had a different meaning and impact, as it carried with it the potential for fostering personal, collaborative, and creative learning. In a way, one-way (one-to-many) communication was thus opened up to the possibilities of interaction, as reflected by the development of Computer-Mediated Communication (CMC).

It can, however, be granted to Critical Pedagogy that the school setting (or the conservative forces that preserve the status quo it represents) is known for entropically fusing any balance-disrupting innovations, with the false promise of easing the educational crisis and promoting social change. On the other hand, Kearsley (1998) warned that "technology has become the great siren song of education" as "(an) enormous amount of attention and resources devoted to the use of technology in the education and training realms distracts us from the really important problems and issues that need to be addressed” (p. 47). Before that, Gozzer (1987) called attention to the error of believing that technology was a panacea for education, the universal cure for the problems that ailed schools and education. This was a recurring error in connection with technological means, and one which computers and Computer Assisted Instruction (CAI) would prove unable to escape (Gozzer, 1987: 15).

In the 1990s, however, ICTs made possible a paradigm shift. It was Jay Lemke (1994) who managed to see further and was able to identify a paradigm war in education, brought about by what he referred to as the information access paradigm and the resulting crisis in the prescribed curriculum. Such evolution has a number of implications, particularly a professional teacher profile where expertise in EdTech design and application goes hand in hand with expertise in the dynamic, articulated, and collaborative construction of knowledge in a shared e-curriculum (Constantino, 2010). Naturally, the inertia of formal education, the threat looming over the teachers' academic authority, and the commercial forces in the publishing industry come up as enemies in front of the idea of an open, incidental curriculum, a multicultural, multilingual and multimedia curriculum. In fact, a curriculum that is to be defined through participation and validated by a teacher who is required to have a high degree of expertise (and, accordingly, of education and responsibility) is perceived as a threat (Constantino, 2010, 2011).

So far in the 21st century, Negroponte's (1995) "mandate" of "being digital" has become a moral obligation for each and every person, in particular for teachers tasked with educating the younger generations defined as "digital natives". EdTech is becoming a pivot for educational practice, insofar as traditional education has ri- 
pened into an outdated, stigmatized model. EdTech resources are virtually endless and constantly improving, with their numbers escalating almost in a geometric progression. Richness and variety are not always, however, a condition for education improvement and quality. For instance, an applied research (Fombona Cadavieco \& Goulao, 2011) for teaching first-order equations using augmented-reality tools does not appear to be an application capable of making an educational difference for students.

\section{EdTech as a Tool for Social Inclusion}

The overcoming of the barriers to quality education through digital literacy (Banzato, 2011) for a major portion of the child and youth population in LA countries has been tackled with "technological inclusion" government programs aimed, precisely, at bridging the digital divide between developed countries and emerging ones. The programs considered to have the greatest impact are those conceived under the OLPC (One Laptop Per Child) paradigm, which was initially promoted by Nicholas Negroponte and his followers (Piscitelli, 2010). Basically, these programs consist in the mass distribution of low-cost laptops with Wi-Fi Internet connectivity to teachers and students at schools, to build a new technology culture in the classroom. The pioneering, mass project in LA is called Plan Ceibal (http://www.ceibal.edu.uy), an initiative which was implemented in Uruguay in 2007 and currently boasts the completed deployment of laptops to all students and teachers at public elementary schools, with coverage of high-schools also in its sights. Along the same line, even though with substantial differences and following an intermittent pattern, Argentina has implemented Programa Conectar Igualdad (Equality Connect Program) (http://www.conectarigualdad.gob.ar) by mid-2013, 3 million laptops had been distributed to an elementary and high-school student headcount of about 8 million.

Without question, this is an amazingly positive initiative as, without the technology devices, without digital tools, the discussion or pondering of EdTech is just a non-starter. However, as academics and researchers of technology-related education problems, it is our obligation to engage in a critical analysis that will yield relevant data and information, as well as theoretical and practical insight, to guide the implementation of these programs and leave errors and bias behind. In this regard, even if commendable and utterly necessary, government programs framed under the OLPC initiative have so far proved insufficient to guarantee the optimal use of the possibilities which the availability of laptops or tablets for use by students and teachers in the classroom has brought about for education. Such optimal use has been conceptualized as the users' ability to achieve the expected (and, accordingly, hoped for) results offered by EdTech where the necessary digital literacy exists. To use an analogy, a proper mount is the first step to riding a horse. These programs have been virtually reduced to providing horses, with a saddle in the best of cases, without ensuring instruction in the art of horse mounting and riding. However, to avoid a useless and recursive discussion of the fact that digital literacy is sterile or straight up impossible without the necessary technological resources, it can be contended that these programs resemble a disembarkment of sorts, a provision of necessary elements to be completed and maintained over time to create and establish a true digital culture, a bridge between technological innovation, digital society, and schools.

A different situation exists at the undergraduate and graduate level. The Latin American Higher Education space has shown exponential growth both in online distance education (mostly through commercial or free platforms) and in blended education tracks (Banzato \& Constantino, 2008). Blended tracks are promoted by university authorities for various reasons, including both the dispersion of the population and the positioning of their institutions in the educational marketplace. In this regard, public universities in Argentina have a budget allocation to fund the technology infrastructure for distance education, outfitting their schools and campuses. Even the Conectar Igualdad Program makes provision for one laptop to be distributed to each university student at the undergraduate level. In other countries such as Colombia, success has been reported in the implementation of EdTech-centered university organization models, which have allowed widespread, decentralized coverage (Herrera Sánchez, 2011).

\section{Teacher Education and Teaching Practice Using EdTech}

In an extensive research work on the interactions between teachers and information technology in education in the areas surrounding the City of Buenos Aires, Cabello et al. (2006) gathered, among other things, data which provide an overview of attitudes towards computers and the Internet, the social representations of teachers regarding technology and its use in schools. From the naïve attitude represented by the phrase "I stay clear of anything computer-related" (title of Cabello's book), this research reveals a range of positions evidencing the 
coexistence of different attitudes which, albeit resting on different reasons, when viewed as a whole do show that there is more than just one digital divide (i.e. not just the one resulting from the possession of technological devices or lack thereof). Of interest here is the conclusion the researchers arrived at, in line with our claim in this paper: considering "access" to EdTech not just in terms of possession and connectivity (in reference to technological devices and the Internet, respectively), but of competence and critical application (p. 285). In other words: considering access to EdTech in terms of digital literacy or technological literacy. In that study, teachers show a favorable disposition towards receiving training that will allow them to make the technology "their own."

A very recent report by the World Bank used the latest report from the PISA standardized testing systemwherein Latin American countries got the lowest scores in the world education ranking-as basis to maintain that the explanation for poor results is not found in the lack of investments (which has doubled over the last decade) but, rather, lies in the inefficient education policies and insufficient training of teachers. Only some of the countries in the region have tackled the issue head on; foremost among them is Chile, which implemented basic knowledge standards for teacher education as well as an evaluation system related to incentives for continuing education.

What do these data tell us about EdTech and TE? First of all, we need to consider the fact that EdTech is complex, interdisciplinary, and dynamic knowledge, and that, accordingly, it calls for education processes of the same kind, including recursive processes (as EdTech is used to teach and learn EdTech). Second, even though there are EdTech academic and professional profiles that push the discipline forward and create applications and expert knowledge, it is teachers who actually design and use EdTech in their classes. Third, if we link the data to these assumptions, we find that there are concrete obstacles to EdTech in LA that relate to teacher education.

A concrete example will illustrate this problem. In the Conectar Igualdad Program referred to in the preceding paragraph, the introduction of laptops into the classroom did not occur hand in hand with specific training for practicing teachers who had never had any digital literacy education, let alone any EdTech training. The modest course offerings were rapidly exceeded. Many teachers had no idea what to do with the laptops, so they continued to provide a traditional teaching experience.

Today, we are fully aware that EdTech is a must in any teacher education curriculum, for teachers practicing at the very first school level and all the way through university. Such a conviction poses a major challenge: What kind of EdTech knowledge should each teacher profile receive, in addition to digital literacy? The goal here is not to have each and every teacher be an EdTech professional or expert, but to have them know what to do with, or be capable of efficiently exploring how to handle, a given technology, content, or teaching situation. To achieve this goal, we need to bear in mind that we are facing several barriers, and will therefore be in need of some bridges or gates.

\section{Barriers and Gates}

The barriers created by the widespread poverty found in several LA countries, which also affects teachers and schools, operate as a strong negative constraint on EdTech design and implementation. The impact of programs focusing on the provision of technology devices is dampened where those programs are carried out in a context of digital illiteracy (at the home, social, or school level). What to do with a laptop or tablet in the classroom? What's something "different and new" that can be done with a digital board? Frustration can appear in both students and teachers alike when neither has enough digital literacy to efficiently and effectively use their technology, and where the social and cultural environment in which they live does not value that device as a "gateway to culture," to use J. Bruner's metaphor (1997).

The barrier created by the social representations (SR) of both the school and its actors, linked to a traditional approach to teaching, can have a concrete effect in the classroom, as SRs shape expectations and behaviors. This is even so where they stand in contradiction with other SRs, such as those regarding digital natives. For instance, we saw a case of a math teacher who implemented the Geo Gebra software in his geometry class but was met with resistance from his teenage students, who claimed that, while at school, they should be using traditional tools (a set square, a compass, and a protractor), rather than a PC.

This example brings us face to face with the generation gap and the "reification" of digital natives: adults do not master digital tools; current technology lies beyond their mindsets. Children and young people were born into this world of technology and, therefore, "know" how to use technology. No much arguing is needed to show 
that, even though children and youths are indeed familiar with digital technology, in general this does not equate to deep, extensive digital competence, but rather superficial knowledge linked to certain elements (such as videogames).

Another barrier consists of teacher education programs designed under a teaching paradigm that is more generalist and traditional than it is specific and technology-minded. This type of teaching creates yet another barrier that has to do with experience and habits. It comes down to a single question: Does EdTech draw any distinction between teaching and learning? Teachers' ponderings along this line are usually questions of teaching economics; the argument is that traditional teaching achieves the same results for a large number of people in a shorter period of time.

A barrier that sometimes goes unnoticed is that put up by the "pre-established uses" of devices and their trasnposition to teaching. Some EdTech implementations are approached by adapting them to a traditional teaching logic, without critical evaluation. For instance, the use of software for multimedia presentations (such as PowerPoint). Many teachers use PowerPoint merely as a blackboard substitute, reproducing textual information rather than taking advantage of its multimedia potential.

At a more general level stands the barrier of the little significance attributed to Instructional Design and, accordingly, EdTech Design. In LA formal Tyler-type models prevail, with typical adaptations to the teaching experience. There is no one professional instructional designer profile, and the role thus falls upon each teacher. As pointed out above, teachers are not properly trained in this area, which, in addition to the unfavorable work conditions they face (overcrowded classrooms, lack of technological tools, low salaries, poor offerings of training in quality services, and so on), leads to a degree of "invisibility" for instructional design with a scientific-technological foundation.

One of the most basic and toughest obstacles is the lack of digital literacy in both teachers and students. Where there are programs and courses in place, the necessary conditions (a negative synergy with the other barriers) for a deep and lasting impact in the classroom are just not met.

One step further up the ladder stands the barrier of multimedia illiteracy (in both students and teachers) and the failure to develop multimedia instruction to train teachers in the use of these learning resources.

The typical geographical distribution of the population in LA, with concentration in large cities and dispersion in rural areas, presents an ambivalent scenario where the weight of the existing barriers and available bridges will be a decisive factor to determine their positive or negative value.

Concurrently, we do recognize certain phenomena which facilitate the adoption and use of technology in education, including both ICTs and EdTech, which we can describe as "gates":

- The increasing "technologization" of society, and the familiarity of children and young people with technological devices (even though this latter factor does not entail Digital Literacy);

- The blending requirement for university courses currently offered by universities in Latin America;

- The current Web of contents (virtual knowledge repositories) that allows a relaxation of the curriculum and the e-curriculum (Constantino, 2010);

- The growth in free and open-source applications that make it possible to use learning tools which would otherwise be outside the reach of a large portion of the population;

- The Social Web, which has brought technology to all sectors of society and follows (and is followed by) the distribution of technological devices.

\section{Conclusions}

In the late 1980s, critical pedagogists such as Peter McLaren warned against an optimistic view of the democratizing and inclusive effects of public schools, as it was a mere illusion, characterized by "broken dreams, false promises" (1988: 41). Ten years later, Kearsley's warning was that "educational technology is primarily a distraction (on a grand scale) from what matters most effective learning and good teaching. In many educational applications it would be far more worthwhile to worry about other things than waste time on technology" (1998: 47). It appears as though time has gone by and the situation remains the same in a major portion of LA. Without question, there are government policies that shape schools and, sometimes in contradiction with the official rhetoric, fail to achieve their ideals of equal opportunity and educational inclusion. Also, commendable initiatives intended to refresh education through EdTech programs are unsuccessful or do not achieve the expected results because of a failure to embrace the contextual complexity and barriers they face. Some of these (structural po- 
verty, social representations of teaching anchored in traditional teaching, reification of youths as digital natives to the detriment of adults, insufficient training of teachers, and so on) are typical, albeit not exclusive, of Latin American education systems. We have, however, also pointed out the existence of "bridges" and "gates," most of them inherent in the development of new technologies (blended learning, open-source software, Social Web, etc.) that facilitate their adoption and use in the classroom. These barriers, - as surveyed in Latin America (Argentina, in particular) - , may not be present at all in developed countries. Moreover, certain "gates" may be completely evident, implicit, and transparent in the school systems of highly-technological societies. However, there is no harm in keeping both types in mind in a contextual and feasibility analysis in the design of EdTech solutions.

Lastly, the teacher as a gatekeeper is a metaphor commonly found in education bibliography. An argument that the overcoming of barriers and the facilitation of access to digital literacy—and to productive EdTech at the service of culture-lies in adequate Teacher Education is, then, in order.

\section{References}

Banzato, M. (2011). Digital Literacy. Milano: Bruno Mondadori.

Banzato, M., \& Constantino, G. D. (2008). Competence Based Tutoring Online. In M. Kendall, \& B. Samways, (Eds.), Learning to Live in the Knowledge Society (pp. 209-216). New York: Springer.

http://dx.doi.org/10.1007/978-0-387-09729-9_32

Black, L. (2013). A History of Scholarship. In M. G. Moore (Ed.), Handbook of Distance Education (pp. 3-30). New York: Routledge.

Bruner, J. (1997). La educación, puerta de la cultura. Madrid: Visor.

Cabello, R. (2006). “Yo con la computadora nada que ver”. Buenos Aires: Prometeo Libros.

Constantino, G. D. (2002). Ch 9: Presenza vitale contro presenza virtuale: studio contrastivo dei modi strategico-discorsivi della interazione didattica (pp. 218-262). In M. Banzato (Ed.), Apprendere in Rete. Torino: UTET.

Constantino, G. D. (2010). Del curriculum interdisciplinar al e-curriculum: Nuevos modelos para la construcción del conocimiento del profesor. RivistaFormazione \& Insegnamento, 8, 77-96.

Constantino, G. D. (2010a). El Análisis del Discurso Didáctico en entornos presenciales y virtuales: Claves conceptuales para la construcción compartida del conocimiento y la enseñanza multimedia. In V. M. Castel, \& L. Cubo de Severino (Eds.), La renovación de la palabra en el bicentenario de la Argentina (pp. 365-371). Mendoza: Editorial FFyL, UNCuyo.

Fombona Cadavieco, J., \& Goulao, M. F. (2011). Educational application of the Augmented Reality. In AA.VV. E-Learning Innovative Models for the Integration of Education, Technology and Research. 5th GUIDE International Conference Proceedings. Roma: GUIDE Association.

Gozzer, G. (1987). Interrelaciones entre sociedad y escuela en la sociedad multicultural y pluralista, Revista del Instituto de Investigaciones Educativas, 13, 3-16.

Herrera Sánchez, G. (2011). Characterization of Academic Networks of theNational Open and DistanceUniversity (UNAD). In AA.VV. E-learning Innovative Models for the Integration of Education, Technology and Research. 5th GUIDE International Conference Proceedings. Roma: GUIDE Association.

Kearsley, G. (1998). Educational Technology: A Critique of Pure Reason. Educational Technology Magazine, 47-51.

Lemke, J. L. (1994). Coming Paradigm Wars in Education: Curriculum Vs Information Access. City University of New York, Brooklyn College, School of Education. [Spanishversion: Las próximas guerras de paradigmas en educación: curriculum vs. acceso a la información, Didaxis online, Vol. 1, 1/2, 20-32.].

Lowenthal, P., \& Wilson, B. G. (2010). Labels Do Matter! A Critique of AECT’s Redefinition of the Field. TechTrends, 54, 38-46. http://dx.doi.org/10.1007/s11528-009-0362-y

McLaren, P. (1988). Broken Dreams, False Promises. Journal of Education, 170, 41-65.

Negroponte, N. (1995). Being Digital. New York: Random House LLC.

Piscitelli, A. (2010). 1@1 Derivas en la educación digital. Buenos Aires: Santillana. 
Scientific Research Publishing (SCIRP) is one of the largest Open Access journal publishers. It is currently publishing more than 200 open access, online, peer-reviewed journals covering a wide range of academic disciplines. SCIRP serves the worldwide academic communities and contributes to the progress and application of science with its publication.

Other selected journals from SCIRP are listed as below. Submit your manuscript to us via either submit@scirp.org or Online Submission Portal.
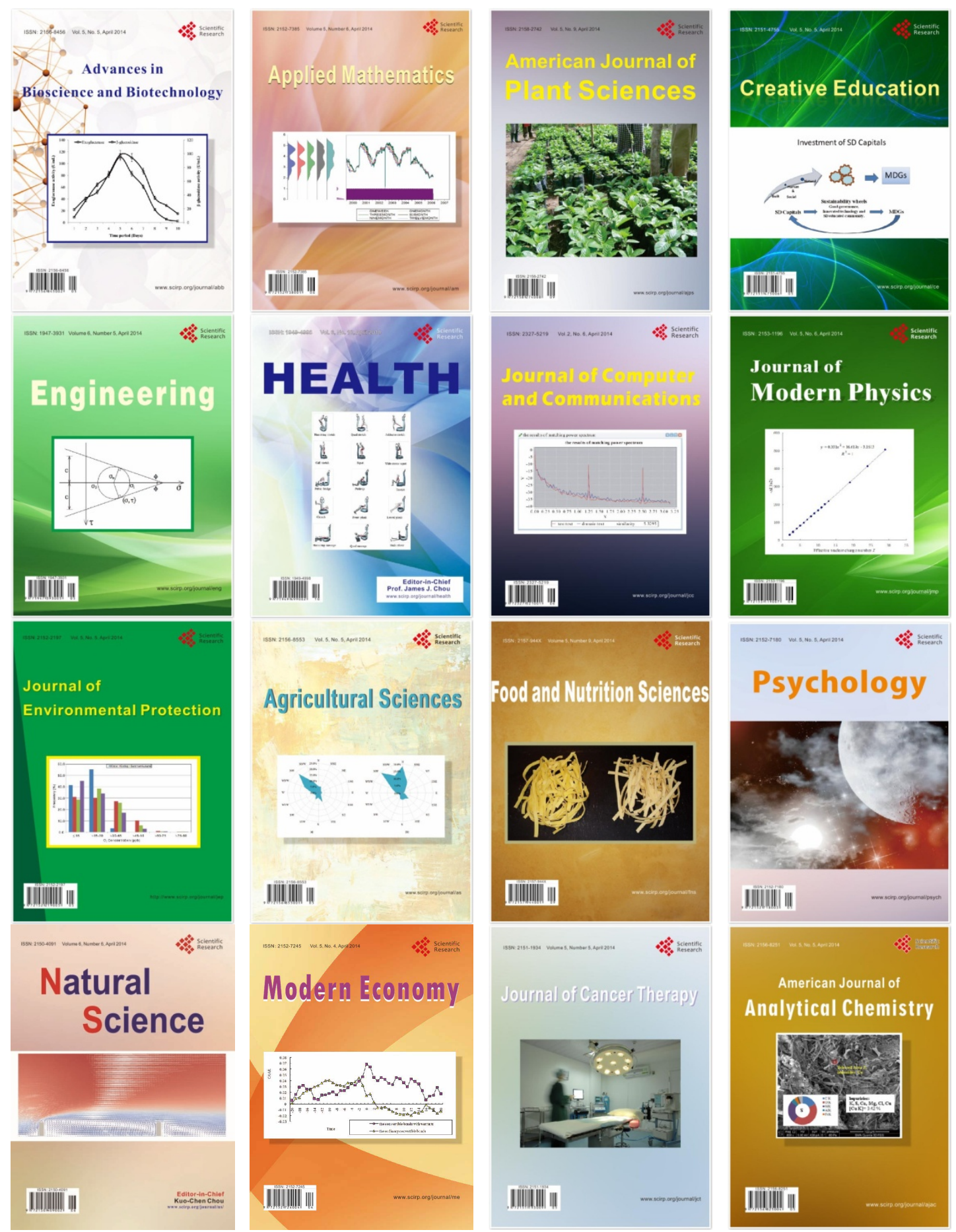